\title{
Correction to: Symptomatic Hypercalcaemia Following the Use of Dissolvable Antibiotic Beads in Infected Total Knee Arthroplasty
}

\author{
Benjamin L Smith ${ }^{1}$ (D) W. Steven Borland ${ }^{1} \cdot$ Thomas Fairhead $^{1}$
}

Published online: 31 January 2020

(C) Springer Nature Switzerland AG 2020

\section{Correction to: SN Comprehensive Clinical Medicine} https://doi.org/10.1007/s42399-019-00189-9

The original article unfortunately contained a mistake. One of the authors, Thomas Fairhead, was not included in the original article.

The original version has been corrected.

The online version of the original article can be found at https://doi.org/ 10.1007/s42399-019-00189-9

\footnotetext{
Benjamin L Smith

Ben070@hotmail.co.uk

W. Steven Borland

Steven.borland@nuth.nhs.uk

Thomas Fairhead

Thomas.Fairhead@nuth.nhs.uk

1 Royal Victoria Infirmary, Queen Victoria Road, Newcastle upon Tyne NE1 4LP, UK
} 